\title{
Características de la demanda de turismo de naturaleza y de aventura en Playa del Carmen
}

\author{
Carlos Raymundo Balderas Elorza \\ Universidad Tecnológica de la Riviera Maya
}

\section{Resumen}

Ante la falta de un concepto de turismo universalmente aceptado, se definió en qué consiste el turismo de naturaleza y aventura en Playa del Carmen y sus características, para homologar conceptos en el contexto de esta investigación empírica, que dará como resultado procesos metodológicos para la obtención de indicadores que permitan medir segmentos turísticos y la demanda de turismo de naturaleza y de aventura en Playa del Carmen para contribuir a la diversificación del destino. La metodología empleada se basa en un proceso cuantitativo de recolección de datos entre turistas con el objeto de detectar las actividades que realizan para establecer porcentualmente cuántos hacen uso de los recursos de naturaleza y de aventura. El resultado ofrece el nivel porcentual de las características y perfil demográfico del turista y cuáles son las principales actividades que desarrolla durante su estancia.

\section{Palabras clave}

Demanda turística, dimensionamiento de la demanda, segmentos turísticos, turismo de naturaleza, turismo de aventura. 


\title{
Characteristics of the demand of nature and adventure tourism in Playa del Carmen, Quintana Roo, Mexico
}

\author{
Carlos Raymundo Balderas Elorza \\ Universidad Tecnológica de la Riviera Maya
}

\begin{abstract}
In determining the nature and adventure tourism segment for Playa del Carmen theoretically defined give details of them and their characteristics, in order to standardize concepts and not leave the research context. As is known tourism faces the problem of not having a universally accepted conceptualization so that complicates their study. This research will consist of an empirical research project, which will result in methodological processes for obtaining tourist segments indicators to measure and determine the extent of the demand for nature and adventure tourism in Playa del Carmen to contribute to the diversification of destiny. The methodology is based on quantitative tourist's data collection in order to detect and identify activities it is the amount of them that makes use of the resources of nature and adventure. The result of the research will give us the percentage level and demographic characteristics of tourists and what are the main tourist activities that develop during their stay.
\end{abstract}

\section{KEY WORDS}

Tourism demand, sizing of demand, tourist segments, nature tourism, adventure tourism.

E-mail: balderaselorza@hotmail.com 


\section{Introducción}

Este trabajo aporta una metodología para identificar qué turistas que viajan a Playa del Carmen motivados por la contemplación de la naturaleza y cuáles para hacer turismo de aventura, esta diferenciación permitirá diversificar el producto turístico regional.

En el primer aparado se exploran los fundamentos y las diferentes teorías del sistema turístico, la demanda turística, los segmentos de turismo, el turismo de naturaleza y el turismo de aventura. Para la comprensión de la presente investigación es preciso entender el turismo y cómo se relacionan sus componentes en un contexto global sistémico desde la visión de Leiper, Boullón y Molina; por otro lado a través del estudio de la demanda turística, se determinan en cierta medida los gustos y las preferencias del visitante, como actor principal del sistema turístico mencionado.

Asimismo, mediante la tipificación de los segmentos turísticos es posible reconocer, aunado a la demanda turística, la decisión en la elección de un destino, identificando las características de los segmentos específicos objetos de estudio a través de las actividades predominantes que los distinguen; el turismo de aventura y de naturaleza.

Posteriormente se aborda la metodología de la investigación a través de la descripción y formulación de objetivos, variables y muestras, y se plantea la forma en la que se desarrollarán los criterios metodológicos. Por último, se analizarán los datos recopilados y se presentarán los resultados de esta investigación, que se propone diferenciar el segmento turístico de naturaleza del de aventura.

\section{Marco teórico-conceptual}

\section{Sistema turístico}

El turismo es una rama incipiente de la economía, de gran importancia por su dinamismo y por el número de sectores económicos que involucra, además de ser una disciplina relativamente joven que no se ha conformado en estructuras conceptuales concretas que faciliten su estudio. Debido a que existe un gran debate sobre los elementos que lo integran, no hay concepciones correctas o incorrectas, sino que dependen del contexto en el que se utilice. 
Autores como Gurría (2007) identifican el producto turístico como la suma de los atractivos turísticos, la infraestructura, la estructura de producción o planta turística y la supraestructura, que fácilmente puede ser confundido con un sistema turístico, y en ocasiones se ve como sinónimo.

El sistema turístico ha sido estudiado con diferentes modelos y distintas perspectivas, las más representativas son las de Leiper, Boullón y Molina.

\section{Modelo de Leiper}

El modelo de sistema de Leiper conceptualiza regiones geográficas divergentes, territorialmente definidas, que permiten que se desarrolle el quehacer turístico, siendo ésta una visión mecánica en la que para cada acción existe una reacción, expulsión y atracción (Quezada, 2007), para lo cual deben existir (véase figura 1):

1. Región de origen. Refiriéndose al territorio desde donde provienen los turistas, que a su vez se entiende como aquel que expulsa personas y recursos monetarios.

2. Región de destino. Es aquel territorio que atrae y abriga a los turistas, conteniendo éste la infraestructura necesaria para resguardarlos, capital humano capacitado y población residente, y

3. Región de tránsito. Que corresponde al territorio entre la región de origen y la región de destino.

El dinamismo de esta región dependerá del medio de transporte que se utilice. Por vía terrestre ofrece la posibilidad de la visita a otros puntos de derrama económica entre las dos regiones por el consumo de energéticos, alimentos y bebidas e incluso hospedaje, dependiendo de la longitud del trayecto.

Cabe puntualizar que autores como Boullón, citado en Cárdenas (2009), definen más variables territoriales que facilitan el estudio geográfico del turismo, tales como espacio turístico, área turística, complejo turístico, núcleo turístico. 


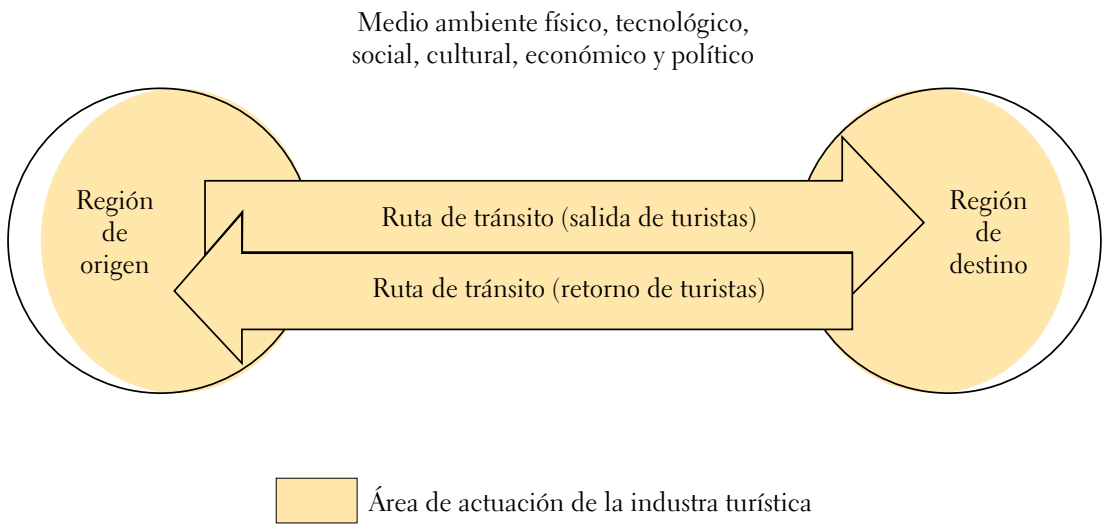

Figura 1. Modelo geográfico de Leiper

\section{Modelo de Boullón}

Se centra en el turismo como una actividad económica. Para Boullón (2004), en este modelo predomina la oferta y la demanda de recursos turísticos (figura 2), sus elementos son:

1. Demanda. Se refiere al producto turístico determinado con un conjunto de atributos, valores y servicios que un turista consume para satisfacer sus necesidades de esparcimiento.

2. Oferta. Bienes y servicios que se colocan en el mercado turístico, en los que el turista efectúa un determinado gasto como en transportación, hospedaje, alimentación, transporte, entretenimiento y ocio, entre otros. En el caso de las agencias de viajes y tours operadores, no forman parte de la oferta, son más bien los intermediarios que acercan la oferta y la demanda; como expresa Sancho (1998), los operadores del mercado.

3. Planta turística. Equipamiento o instalaciones propias del sistema: restaurantes, hoteles, centros de entretenimiento y la infraestructura necesaria para comunicarse y acceder; carreteras, puertos, centrales camioneras, aeropuertos requeridos para satisfacer la demanda turística. 
4. Supraestructura. Parte del sistema que conlleva la acción de organismos que fomentan el financiamiento, la legislación y la promoción de la actividad turística, ya sea de forma privada o pública.

5. Producto turístico. Resultado de la suma de la oferta, la planta turística, supraestructura y un elemento implícito dentro de la oferta turística, sin los cuales no existe la actividad como tal y nos referimos a los atractivos turísticos.

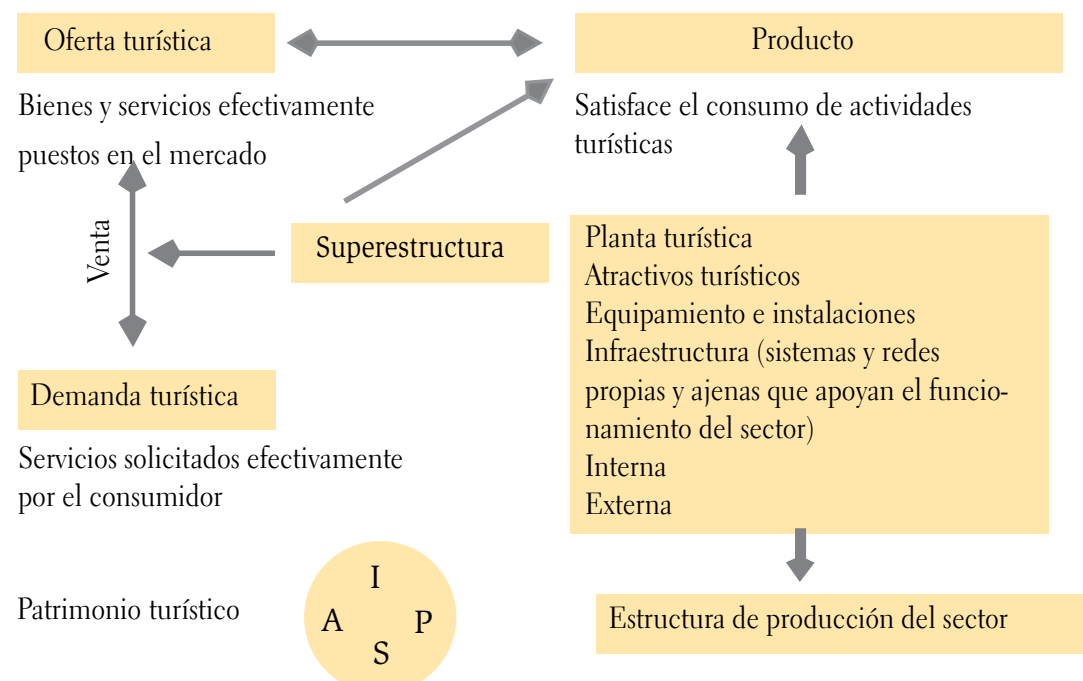

Figura 2. Modelo económico de Boullón

\section{Modelo de Molina}

Este modelo integra a la comunidad receptora como elemento distintivo del quehacer turístico, ya que las características son determinantes para el desarrollo del turismo (Molina, 1997) (figura 3). 
1. Surpaestructura. Regula el sistema turístico mediante organismos tanto privados como públicos, estos últimos centrado en políticas, leyes, reglamentos planes y programas.

2. Demanda. Que se constituye sustancialmente por los individuos; los turistas con sus necesidades, que van desde la alimentación hasta el aprendizaje y la autorrealización, y que se enmarcan en una tipificación de acuerdo con los segmentos psicográficos individuales.

3. Atractivos. Que como fundamento del desplazamiento turístico comprende tanto los naturales como los culturales.

4. Equipamiento e instalaciones. Se refiere a los establecimientos que permiten la permanencia del turista, y comprende a los de hospedaje, camping, de alimentos y bebidas, agencias de viajes, campos de golf, spas, albercas.

5. Infraestructura. Son los prestadores de servicios básicos y de apoyo como, los aeropuertos, telégrafos, redes de comunicación, alcantarillado, agua potable.

6. Comunidad receptora, que directa o indirectamente tiene relación con el turismo.

\section{SISTEMA TURÍSTICO}

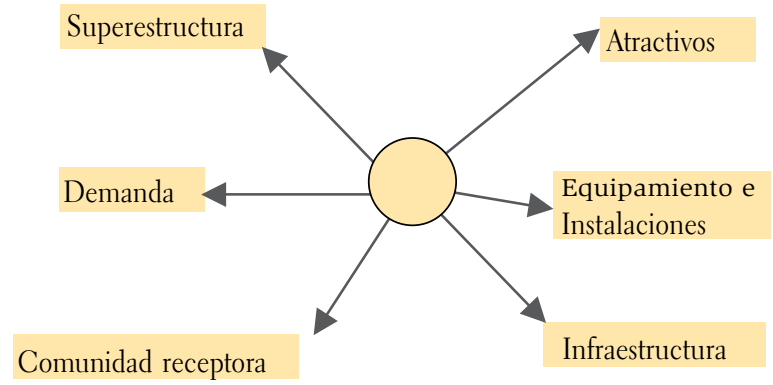

Supersistema Socio-cultural (entorno)

Figura 3. Sistema turístico de Molina 
Agregándole al modelo de sistema turístico de Molina el elemento denominado actividad turística predominante, facultará el desarrollo de la presente investigación; siendo éste el elemento intrínseco del turista que se puede definir como característica propia del turista, en este apartado se enmarca en un segmento turístico y que denota los gustos en actividades del turista y que aunado a la supraestructura, la demanda, los atractivos (naturales y culturales), el equipamiento e instalaciones y la comunidad receptora conciertan la decisión final de un turista para elegir un destino (figura 4).

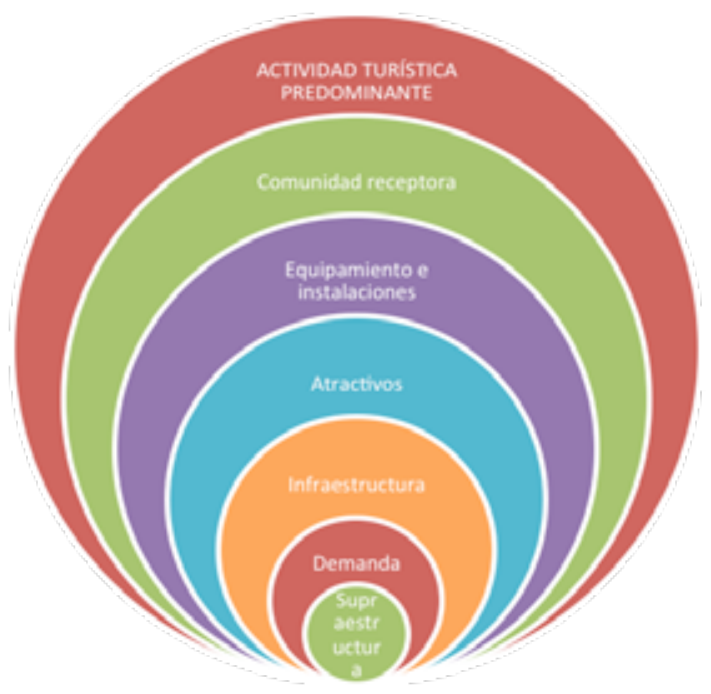

Figura 4. Elaboración propia, basado en el sistema turístico de Molina

\section{Motivos de viaje}

El sistema turístico entra en funcionamiento a través de su elemento dinámico; es decir, el turista que toma su decisión de viaje por una serie de motivos inherentes a los atributos del propio destino, a los servicios, o a la actividad que pretende realizar. En ese sentido se identifican los principales motivos de los 
viajes (Acerenza, 2003), que a su vez dan origen a los diversos tipos de turismo, que se expresan de la siguiente manera:

- Motivos vacacionales o convencionales. Relacionados con aspectos culturales, el descanso y el placer responden a las siguientes razones: relajamiento, práctica de deportes, diversión, conocer lugares diferentes, relaciones interpersonales, prestigio y estatus social.

- Motivos de turismo especializado. Relacionado con el deseo de tener nuevas experiencias o conocimiento de flora, fauna u otros, y atiende a las siguientes razones: expectativas de emoción, aventura e interés científico.

- Motivos del turismo de afinidad. Que atienden a intereses comunes como la religión o una filosofía de vida; sus principales razones son: profesionales, de negocios y espirituales.

Los recursos que utiliza un turista durante sus vacaciones puede cambiar 0 complementar el propósito inicial del viaje.

Para la Organización Mundial de Turismo (2012): "el propósito principal de un viaje se define como el propósito que en su ausencia, el viaje no hubiera tenido lugar”. El propósito del viaje puede clasificarse en las siguientes categorías:

\section{Personal}

1.1. Vacaciones, ocio y tiempo libre

1.2. Visitar a los amigos y familiares

1.3. Educación y formación

1.4. Salud y atención médica

1.5. Religión / peregrinaciones

1.6. Compras

1.7. Tránsito

1.8. Otro

\section{Empresarial y profesional}

La clasificación de un viaje de acuerdo con su propósito debe estar relacionada con las actividades que se realizan, aunque el visitante también puede efectuar actividades secundarias. 
Para efectos de esta investigación los propósitos que se considerarán son vacaciones, ocio y tiempo libre, categoría que incluye, por ejemplo, la visita a sitios naturales o intervenidos por el hombre para eventos deportivos o culturales; la práctica de un deporte (esquí, equitación, golf, tenis, buceo, surf, senderismo, montañismo, etc.) como una actividad no profesional para ser realizada en la playa, piscina y cualquier otra instalación de recreación y entretenimiento; cruceros, juegos de azar; campamentos de verano para jóvenes; viaje de luna de miel; visita a restaurantes o establecimientos especializados en el bienestar.

\section{Demanda turística}

En términos turísticos la demanda se connota en un sentido diverso a su versión económica donde se muestran las distintas cantidades de un bien que un consumidor está dispuesto a adquirir; según Macintosh (2008), la demanda turística se encuentra fuertemente ligada, por un lado, con la propensión que incluye factores psicográficos, demográficos y mercadológicos; y, por otro, con la resistencia: distancia económica, distancia cultural, costo de los servicios turísticos, calidad de los servicios y la temporada, que en otros términos sería una demanda potencial; sin embargo existe la demanda real, es decir, las personas que ya vencieron las resistencias y que se encuentran en un destino, ésta nos permite obtener valores relacionados con las llegadas de visitantes, número de días o noche por visitante y cantidades gastadas.

Como se puede apreciar, la gama que mide la demanda turística es extensa y por ende difícil de asimilar, ya que los parámetros son muy diversos y distantes entre sí. La demanda en el estricto sentido no es estática, se encuentra marcada por tendencias, sobre todo en relación con los aspectos socioculturales que influyen en el comportamiento del consumidor (Vignati, 2009).

\section{Segmentos del turismo}

Para la Secretaría de Turismo (Sectur, 2012) existen diferentes segmentos turísticos: turismo alternativo, cultural y de salud, deportivo y náutico, de negocios, turismo para todos y otros segmentos especializados. A través de la Dirección General de Desarrollo de Productos Turísticos, Sectur se encarga de impulsar el desarrollo competitivo de nuevos productos turísticos, así como el apoyo a 
la profesionalización y vinculación empresarial de los prestadores de servicios turísticos mediante la caracterización de los segmentos.

De la Torre Padilla (2012) tipifica el turismo de acuerdo con diferentes aspectos, como su origen, su permanencia y forma de viaje; para determinar el segmento analiza la motivación de viajero: recreación, descanso, cultura y salud.

Como se puede apreciar, los segmentos de turismo son tan variados como los gustos y preferencias de los turistas, además de las tendencias en un mundo vanguardista e innovador que no se detiene y busca nuevas alternativas de hacer turismo. No existe una homogenización de los segmentos, lo que dificulta su entendimiento, además de que éstos se pueden combinar, lo que provoca que un turista esté facultado para interactuar entre segmentos sin el mayor de los problemas, de manera consciente o inconsciente; por ejemplo, si se encuentra en un segmento de sol y playa eso no le impide que realice otras actividades características de otro segmento.

\section{Turismo de naturaleza}

Vivir la experiencia de encontrarse entre flora y fauna silvestres en un entorno lo más natural posible se identifica con el concepto de turismo centrado en la naturaleza y a su vez define el concepto de ecoturismo. La concienciación cada vez mayor sobre el medio ambiente, junto con la mayor accesibilidad a lugares remotos (hasta ahora inaccesibles), han propiciado que esta modalidad turística este experimentado un rápido crecimiento. La observación de ballenas, las visitas a las selvas tropicales y a los hábitats de los grandes mamíferos vienen a complementar otras actividades más tradicionales como la observación de aves y la contemplación de escenarios de gran belleza paisajística en diversos parques naturales.

Geoffrey Wall, en la Enciclopedia del turismo (2000) define ecoturismo como "el turismo que consiste en viajar a espacios naturales o silvestres relativamente vírgenes o inexplorados con el objetivo específico de estudiar, admirar y disfrutar el escenario natural, su flora y su fauna, así como de cualquier manifestación cultural (tanto pasada como presente) que se pueda encontrar en esas zonas”. 


\section{Turismo de aventura}

Es otra de las modalidades del turismo alternativo llamado también turismo deportivo, turismo de reto o turismo de adrenalina, aunque el término más extendido y generalizado es el de turismo de aventura; el cual se empezó a desarrollar como una oferta potencial derivado de las prácticas deportivas realizadas por muchas personas sin que se viera como una posibilidad de hacer negocio (Zamorano, 2009). Los aficionados a escalada en roca, alpinismo o buceo realizaban estas actividades por el gusto de hacerlas, pero las miradas del turismo se volcaron hacia estas actividades debido a la demanda de actividades distintas y en parte por el poco dinamismo de los centros turísticos tradicionales. Las nuevas prácticas representaron un gran reto al no existir el personal capacitado, de conducción o guía, seguridad y en muchos casos un marco legal, independientemente de esto los servicios de turismo de aventura que se prestan -algunos de manera muy profesional y otros ciertamente de manera improvisada- representan un segmento muy socorrido. Las actividades más favorecidas del turismo de aventura son: trekking, rafting, kayak de mar, escalada en roca, alpinismo de alta montaña, ciclismo de montaña, parapente, hanggliding, buceo, surfing y paracaidismo.

\section{Antecedentes de Playa del Carmen}

La historia moderna de Playa del Carmen comenzó con el arribo de las primeras familias provenientes de la Península de Yucatán, obligadas por las contingencias de la guerra de castas (1847-1901) a buscar tierras menos conflictivas donde establecerse, y se esparcieron en distintos puntos, como Cozumel y parte de la zona continental.

También se dice que al ser contratados como chicleros, algunos desertaron y decidieron trabajar por su propia cuenta como pescadores, dejando su vida errante para quedarse a vivir en estas tierras. A partir de entonces comienza un lento desarrollo, propiciado por el crecimiento de las familias a partir de nuevos matrimonios entre la gente local y con inmigrantes.

El centro de Playa del Carmen estuvo por mucho tiempo en lo que ahora es la Calle Seis en la zona federal marítima terrestre y la Quinta Avenida, y en ese tiempo a la comunidad se le conoció como Playa Morentes siendo al 
principio una incipiente comunidad de cuatro o cinco palapas de huano. De los sesenta en adelante empieza un rápido y progresivo crecimiento de la población, a partir de entonces Playa del Carmen deja de ser un lugar de paso hacia Cozumel y comienza a tener actividad económica. Sin embargo, en el aspecto político, aún venían de Cozumel los nombramientos para los primeros subdelegados y posteriormente los delegados.

\section{Metodología}

\section{Justificación}

Cuantificar el tamaño del mercado de una determinada región tiene por objeto encaminar los recursos de inversión, desarrollo regional y promoción de los diferentes productos turísticos. En ese sentido diseñar productos turísticos tiene como fundamento integrar los recursos turísticos: atractivos naturales o culturales, servicios e infraestructura de un destino o región; elementos que son considerados por los turistas en la planeación y organización de su viaje.

La demanda turística, en su dinámica constante, interviene en los estilos de vida de los turistas, sus hábitos de viajes, sus preferencias, tendencias, actividades y tours que los destinos ofrecen, por lo que se requiere dividir la demanda turística, a partir de la identificación de grupos homogéneos que tengan en común una serie de variables que los hacen diferentes entre sí, y que los convierten en grupos de un interés especial de acuerdo con los recursos que utilizan.

Cuantificar y clasificar a los turistas por el tipo de oferta que consumen; los recursos turísticos que demandan; por tipo de destino que visitan; por el gasto, o bien por el tipo de actividad es complejo, ya que en un mismo destino se pueden desarrollar o consumir diferentes recursos turísticos.

Se ha comprobado que un turista acostumbra consumir uno o varios tipos de recursos en un mismo viaje, por lo que se busca medir el nivel de especialización o intensidad con la que consume cada tipo de recurso, identificando cuál toma mayor relevancia durante su viaje. Por otro lado, el interés por elaborar este trabajo de investigación surge porque no existe información relativa a los segmentos de mercado y los recursos que consumen, información que nos permitiría realizar estudios mercadológicos y de promoción más pertinentes. 


\section{Objetivos}

\section{Objetivo general}

- Determinar la dimensión de la demanda del turismo de naturaleza y de aventura en Playa del Carmen, mediante el desarrollo de indicadores, para contribuir a la diversificación del destino.

\section{Objetivos específicos}

- Generar indicadores mediante la determinación de variables de medición de los segmentos a través de un modelo de estimación para determinar el grado porcentual de turistas que utilizan recursos de turismo de naturaleza y aventura

- Determinar las características de los turistas de naturaleza y los turistas de aventura mediante el perfil sociodemográfico, motivo y propósito de viaje.

- Identificar las actividades del segmento de turismo de naturaleza y de aventura para contribuir a la diversificación del destino.

\section{Variables}

A partir del universo de estudio se obtendrán datos que nos permitirán obtener información necesaria para determinar el segmento de turismo que consume recursos de naturaleza y aventura en Playa del Carmen. Estos datos corresponden a las unidades de análisis, los cuales son los entes o elementos a analizar que poseen cualidades o atributos conocidos como variables; que a su vez tienen determinadas cualidades. Las variables a su vez poseen características denominadas valores. A continuación se detallan las unidades de análisis, las variables y sus respectivos valores para así confeccionar el instrumento de recolección de datos.

- Unidad de análisis 1: Turistas que se encuentran en Playa del Carmen en el periodo de octubre-noviembre 2012. Variables: edad, sexo, profesión u ocupación, nivel de estudios, lugar de residencia, con quien 
realiza el viaje, transporte utilizado, tiempo promedio de estancia, motivo principal del viaje, frecuencia de visita.

- Unidad de análisis 2: Sobre las actividades turísticas que realizan durante su viaje. Variables: cultural, sol y playa, alternativas.

- Unidad de análisis 3: Sobre las actividades especializadas de naturaleza que el turista realiza durante su viaje. Variables: naturaleza.

- Unidad de análisis 4: Sobre las actividades especializadas de aventura que el turista realiza durante su viaje. Variables: terrestres, acuáticas, aéreas

\section{Diseño del instrumento de recolección de datos}

El instrumento que se utilizó para llevar a cabo la recolección de datos fue una encuesta realizada en español y en inglés para que tanto el encuestador como el turista se sintieran más cómodos y no cambiaran el sentido de las preguntas en una traducción. Se tomaron en cuenta para su realización las unidades de análisis, variables y los valores de cada una de las variables de análisis.

\section{Muestra}

Para la aplicación de las encuestas el tipo de muestreo fue no probabilístico causal; es decir, no se estableció el número de elementos que participaron en ella, puesto que la selección de los encuestados dependió de la voluntad del turista y del criterio del encuestador.

No se establece con antelación la cantidad exacta de encuestas, sino que se efectúan hasta saturar la muestra; o sea, en el momento en que la obtención de datos sea reincidente. Esta muestra dependerá de qué tan homogénea o heterogénea sea el objeto de estudio; entre más homogénea, más pequeña la muestra. En este caso la muestra se saturó con 152 muestras ya que en la variable que indica el motivo principal del viaje, una de las cinco unidades de análisis, alcanzo casi $70 \%$, obteniendo así una reincidencia de datos.

La ventaja de una muestra no probabilística desde la visión cuantitativa es su utilidad para un determinado diseño de estudio que no requiere tanto una representatividad. En el caso de esta investigación la muestra no es distintiva, ya que el lapso de toma de las muestras no contempla las diferentes temporadas vacacionales que le den representatividad. 


\section{Instrumentos de medición y técnicas}

En este proceso de investigación el proceso de recolección de datos se hizo a través de fuentes de información primarias.

Levantamiento de campo. Se pretendía entrevistar tanto a turistas nacionales como a internacionales, los participantes deberían presentar una propuesta para el muestreo, cumpliendo con las especificaciones siguientes:

Técnica y sujeto de estudio. Se debía realizar una encuesta cara a cara con turistas nacionales y extranjeros mayores de 18 años en la Quinta Avenida y en el área de la playa (zona predominantemente turística de Playa del Carmen), que hubiesen pernoctado al menos una noche en el destino y su propósito principal del viaje haya sido alguno de los siguientes:

a) Viaje de placer, esparcimiento o recreación

b) Viaje relacionado directamente con el contacto con la naturaleza y la aventura

Con base en los resultados se determinó la dimensión del mercado de cada segmento turístico: alternativo (naturaleza y aventura), cultural, sol y playa, y otros.

\section{Preguntas de investigación}

Con base en lo expuesto, se tiene que los proyectos de investigación sobre Playa del Carmen miden factores que identifican los segmentos de mercado, sin embargo falta la cuantificación de los recursos que utiliza cada uno de los segmentos de turismo. Por ello se plantean las siguientes preguntas de investigación: ¿Se puede identificar el segmento turístico al que pertenecen los visitantes a través de las actividades que realizan durante su viaje? ¿Las actividades realizadas determina el motivo principal de un viaje? ¿Es Playa del Carmen un destino donde predominan los turistas del segmento de naturaleza y aventura?

\section{Tipo de investigación}

La investigación es de carácter cuantitativo y probatorio, parte de una idea que va delimitándose, se derivan objetivos y preguntas de investigación, se revisa la literatura y se construye un marco teórico para posteriormente establecer 
hipótesis y determinar variables, para después desarrollar el diseño de la investigación, seleccionar una muestra, recolectar datos, analizarlos y elaborar un reporte de resultados.

El alcance de la presente investigación es del tipo exploratorio-descriptivo. Según Hernández Sampieri (2010) los estudios exploratorios sirven cuando no hay información sobre el objeto de estudio o ha sido poco estudiado, por lo cual se tiene que delimitar el problema y se analiza la información precisa, permitiendo así sentar bases o "preparar el camino"; posteriormente, en la etapa descriptiva se plantea la problemática y se trabaja con la información obtenida, previamente sistematizada, capaz de precisar qué y cómo se medirá.

En este tipo de alcance la hipótesis puede no existir o generarse a lo largo de la investigación.

\section{Proceso metodológico}

Se definen en primera instancia cuáles son las actividades asociadas a un segmento turístico para determinar si un turista ha consumido determinado recurso turístico y su nivel especialización; es decir, si un turista se puede catalogar, por ejemplo, como de interés ocasional en la cultura (que durante su viaje desarrolló alguna actividad cultural) o de interés especial (que en su viaje tuvieron una importancia relativa las actividades culturales en el destino), y de esta manera para los tres tipos de recursos turístico.

Para desarrollar el instrumento de investigación, se consideraron las definiciones de la Organización Mundial del Turismo en cuanto al propósito del viaje. Con la intención de poseer resultados homólogos a dicha organización. De esta manera, se podrá ligar el propósito del viaje, con motivaciones particulares, las actividades realizadas para cada recurso turístico existente.

Mediante la aplicación de instrumentos de recolección de dados se determinó la intensidad de cada una de las actividades realizadas por el turista en relación con el tipo de recurso consumido, la relevancia que tuvieron para el propio turista las actividades realizadas, identificando cuál fue de mayor importancia en su viaje. En la encuesta se preguntó sobre la principal actividad que se pretendía hacer durante el viaje, se ponderó respecto a otras actividades realizadas y se incluyeron variables sociodemográficas. 
Un mismo turista podía clasificar para los tres tipos de recursos turísticos. La intención de la investigación fue determinar el porcentaje de turistas que consumía principalmente los recursos de naturaleza y aventura, y su nivel de especialización.

De esta manera, se buscó identificar grupos de turistas que consumieron determinado recurso turístico, de acuerdo con las actividades que desarrollaron para conocer el propósito, motivación de viaje y sus características socioeconómicas.

\section{Hipótesis de trabajo}

La intención de esta investigación fue identificar grupos de turistas, dependiendo del recurso turístico consumido, en el entendido que no son mutuamente excluyentes y que tampoco existe el turista puro, es decir, que sólo consume un tipo de recurso. Dado el peso específico que tiene el producto de sol y playa, se considera como un recurso adicional, aunque estrictamente hablando debería de formar parte del recurso natural.

Considerando lo anterior, para el desarrollo de la investigación se plantearon las siguientes hipótesis, aunque cabe destacar que no se comprobaron ya que la muestra no fue significativa, por lo que no se podían sacar medidas de tendencia central y, por ende, la varianza y el error muestral.

Hi1: Las principales actividades realizadas por los turistas en Playa del Carmen son las de carácter cultural, alternativas y las de sol y playa.

Ho1: Las principales actividades realizadas por los turistas en Playa del Carmen no son las de carácter cultural, alternativas y las de sol y playa.

Ha1: Las actividades complementarias realizadas por los turistas en Playa del Carmen son las de carácter cultural, alternativas y las de sol y playa.

\section{Resultados}

Para entender el comportamiento de los segmentos estudiados se analizó la información a partir de la distribución de frecuencias para proceder a la interpretación de la información con los datos fríos. 
Para definir la dimensión que poseen los segmentos de turismo de aventura y de naturaleza en Playa del Carmen se realizaron inferencias de datos entre la muestra y los segmentos específicos.

\section{Análisis e interpretación de datos}

La información recopilada en las encuestas tiene como finalidad servir como fundamento para dimensionar el turismo de naturaleza y de aventura.

El sector predominante en la muestra fue el sexo masculino, por encima de la mitad, con $57 \%$ en contraparte de $43 \%$ del sexo femenino.

Para la figura 5 y con el propósito de simplificar los datos, se tomaron cuatro grupos de rangos de edad partiendo de los 18 años, ya que en la delimitación del objeto de estudio se considera este dato como mínimo valido para la investigación. Prácticamente la mitad de la muestra corresponde al rango de edad de 18 a 35 años, seguido por un tercio de la muestra que se ubica en el rango de edad de 36 a 45 años. Lo que permite observar que el turismo que llega a Playa del Carmen es joven, existiendo una minoría de personas mayores de 60 años.

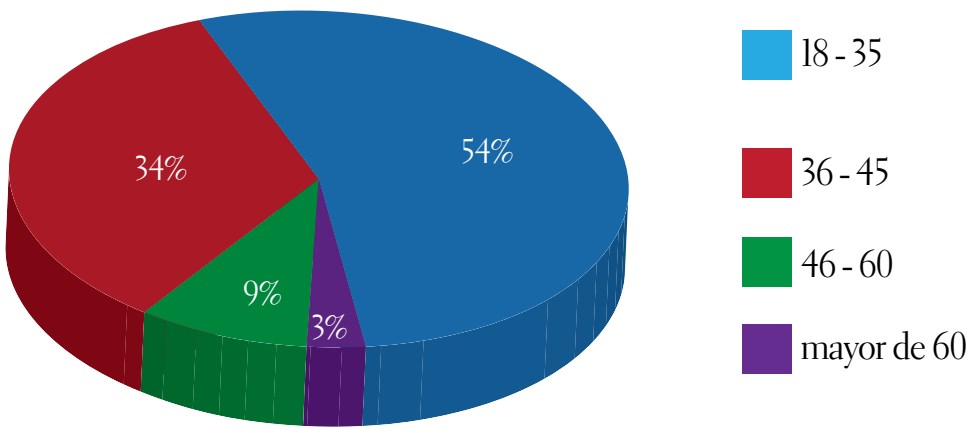

Figura 5. Edad de la demanda turística en Playa del Carmen 
Más de la tercera parte de los visitantes de Playa del Carmen son profesionistas, en este rango pueden entrar personas que trabajan por asesorías o que tienen su propia fuente de ingresos, seguido por estudiantes y después por personas que dependen de terceros, casi con un mismo porcentaje se encuentran amas de casa y personas jubiladas, dejando en último lugar a los desempleados (figura 6).

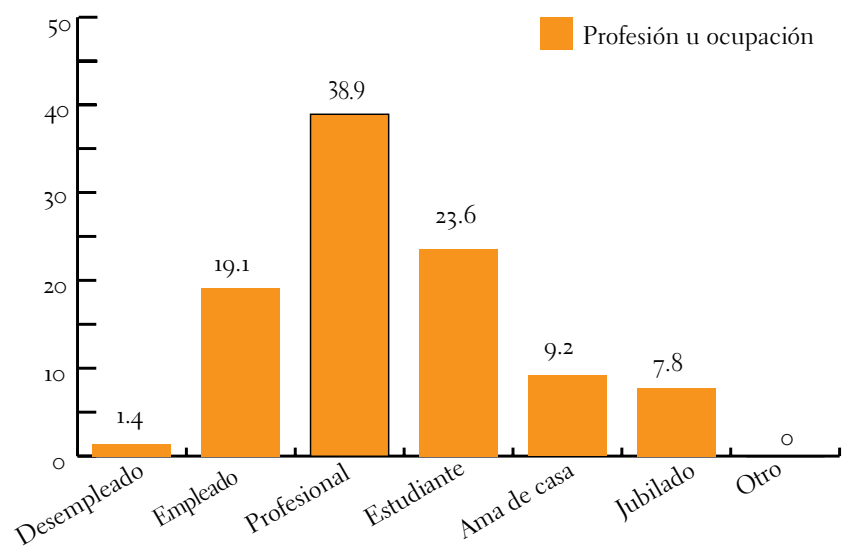

Figura 6. Profesión u ocupación

Con respecto al nivel de estudios de las turistas que visitan Playa del Carmen dos terceras partes de los encuestados tienen una formación universitaria, seguido de turistas con preparatoria y en un grado menor de personas con estudios de posgrado (figura 7).
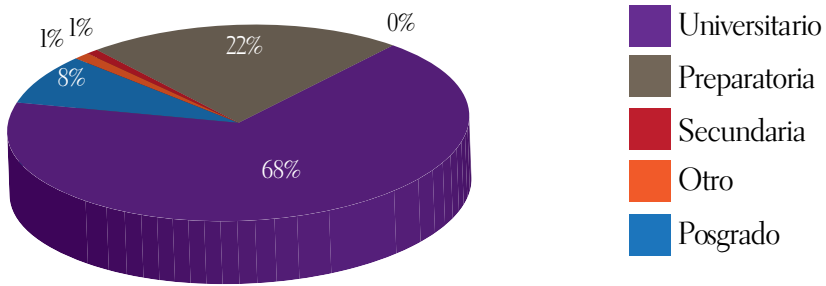

Figura 7. Nivel de estudios 
En la figura 8 se puede apreciar que la mayor afluencia de turistas a Playa del Carmen procede del interior del país en un porcentaje de $57 \%$ seguido por $29 \%$ de Estados Unidos y Canadá, 7.8\% de europeos y el resto de diferentes partes del mundo. Cabe destacar que los segmentos de asiáticos y sudamericanos se encuentran en igual proporción, lo cual llama la atención por la distancia geográfica.
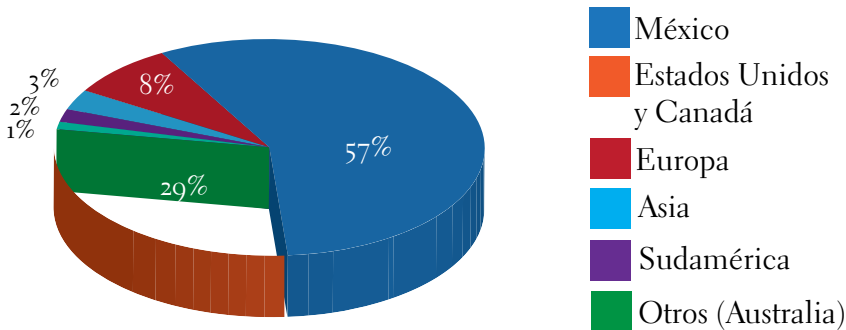

Figura 8. Procedencia del turismo por región

En la figura 9 se observa que el primer lugar de procedencia de los turistas nacionales, corresponde a la entidad federativa de mayor población: el D.F. ocupa $43.4 \%$ de la afluencia turística, seguido por Guadalajara y Monterrey con $10.3 \%$ y $9 \%$ respectivamente. Por otro lado, tampoco sorprende que lugares como Mérida y Veracruz sigan en cuarta y quinta posición, por la cercanía. Esta información es de gran importancia porque permitirá dirigir los esfuerzos publicitarios a los centros emisores (figura 9).

Por lo que respecta a segmento norteamericano, dos terceras partes son ocupadas por el mercado estadounidense (68\%), lo cual no sorprende por la cercanía de este país. El segmento canadiense (32\%) representa una tercera parte de ese mercado. En lo que respecta a la afluencia europea se puede identificar un mercado inglés que abarca $25 \%$, así como el mercado español y francés con porcentajes muy similares; sin embargo, la gran mayoría, $58 \%$, sólo se identificó como europeo (figura 10).

Lo que se puede analizar en la figura 11 es que la mitad de la afluencia de sudamericanos procede de Brasil, lo cual es de esperarse debido a que se consi- 


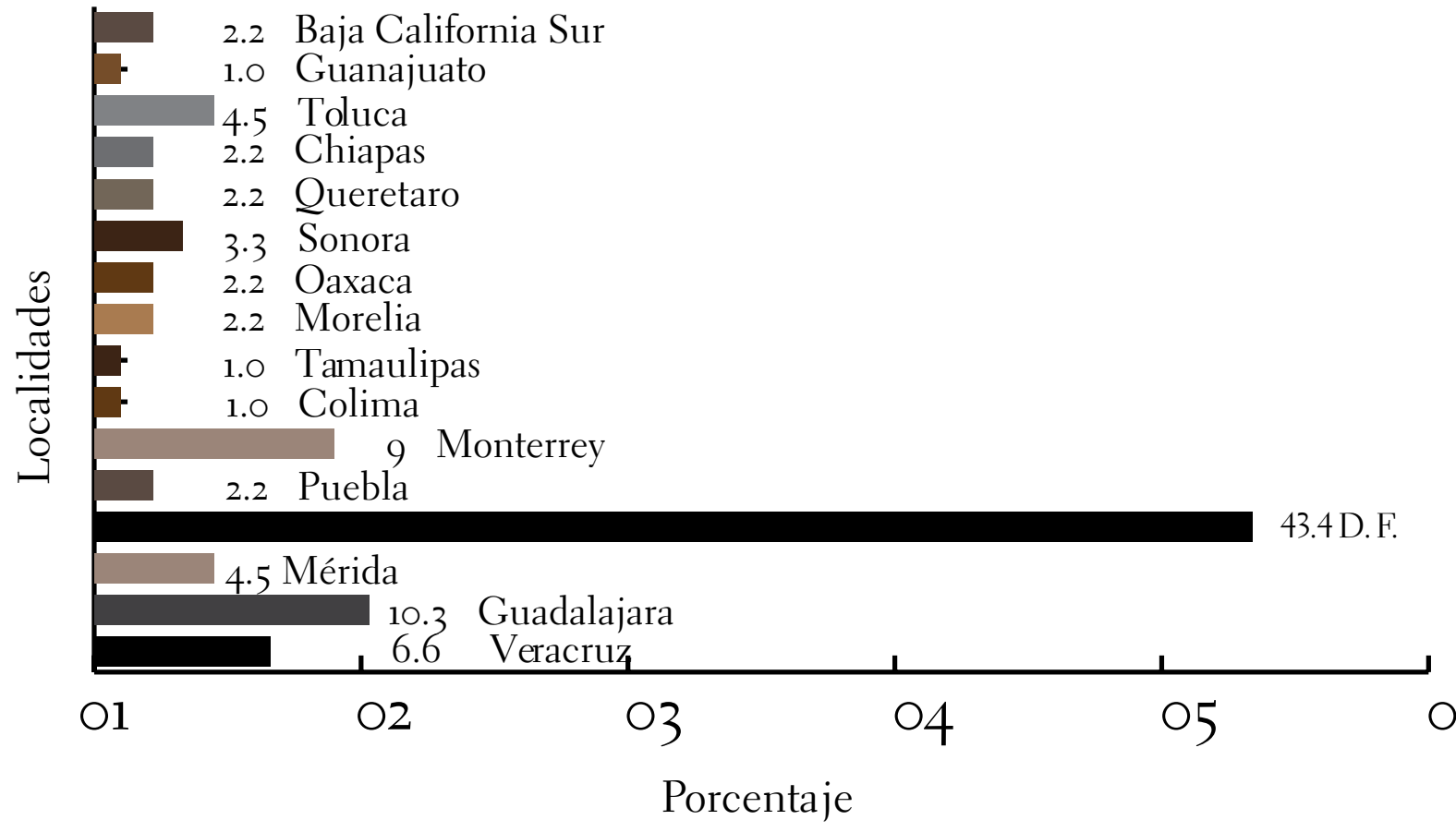

Figura 9. Procedencia del turismo nacional

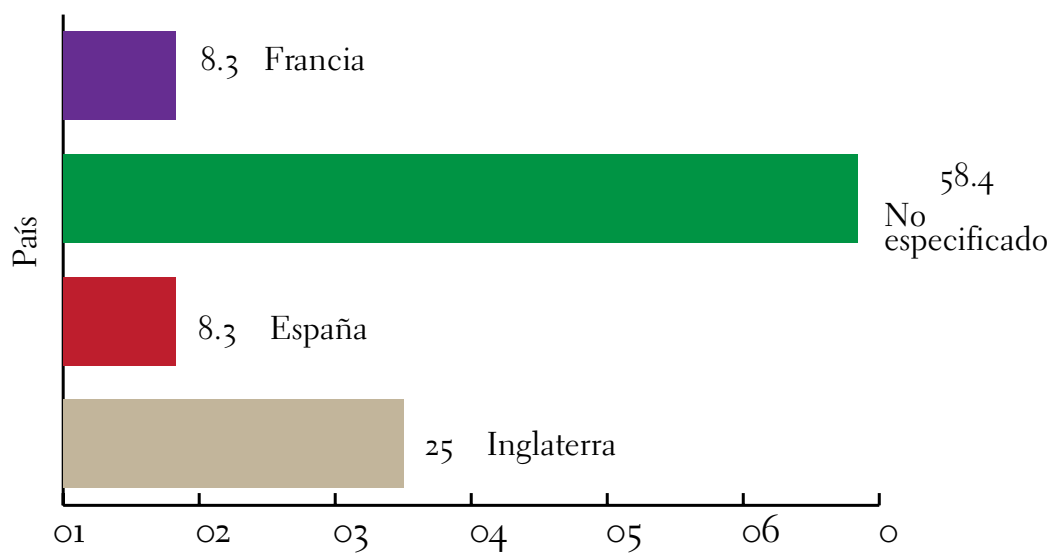

Figura 10. Procedencia del turismo europeo 
dera, junto con China e India, una de las economías emergentes más importantes del momento. La otra mitad se divide entre Colombia y Argentina, a partes iguales. En lo que respecta al mercado asiático China ocupa $75 \%$ e Israel $25 \%$.

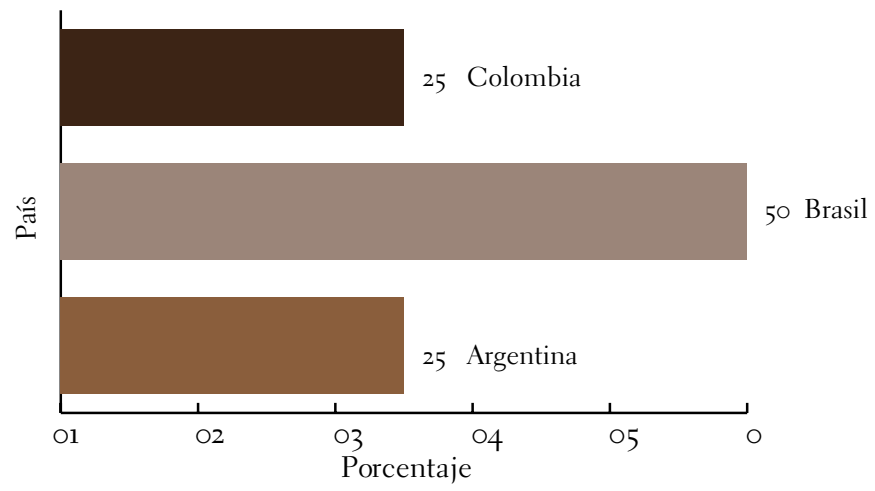

Figura 11. Procedencia sudamericano

Como se puede apreciar en la figura 12 los segmentos viaje con amigos y con pareja se encuentran muy parejos, y se distingue una predominancia de los viajes con familia con poco más de la tercera parte de la muestra. Con un porcentaje muy bajo se ubica el segmento de otro, que es representado por viaje con compañeros de trabajo, y aunque el destino tiene hoteles especializados en grupos y convenciones, éstos por lo general se encuentran haciendo actividades en los hoteles o grupales, por lo cual no son tan representativos en la muestra.

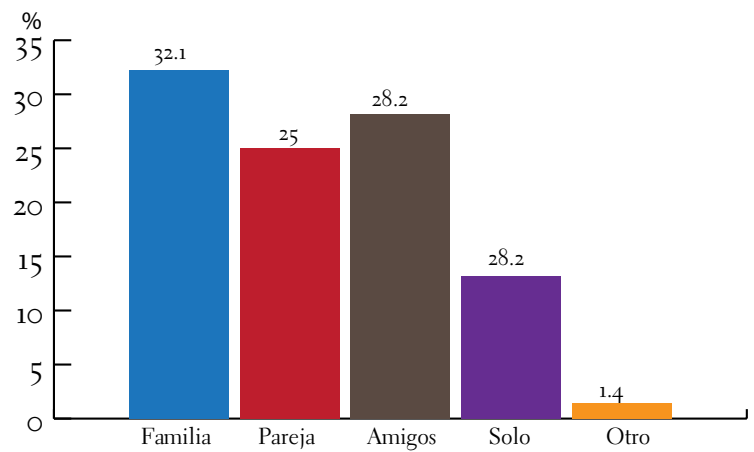

Figura 12. ¿Con quién viaja? 
En la figura 13 se observa que el medio de transporte principal para acceder a Playa del Carmen es aéreo, con 79\% de la muestra; esto es justamente por la distancia de los centros emisores, principalmente los extranjeros; en lo que respecta a los nacionales los primordiales centros emisores se encuentran a más de 24 horas por vía terrestre, de ahí la preferencia en el uso de avión; los que llegan por vía terrestre ya sea en autobús o con vehículo propio, en su mayoría vienen de regiones aledañas.

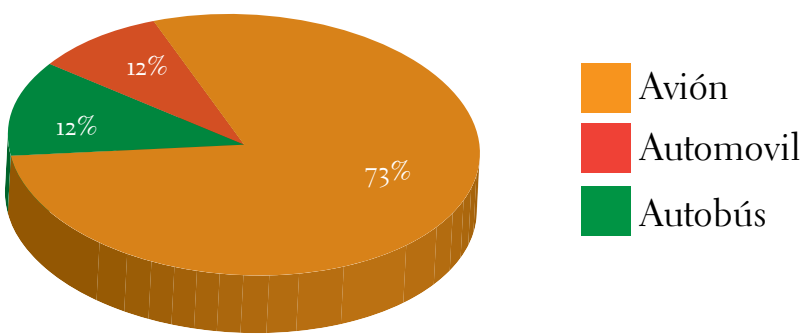

Figura 13. Medio de transporte utilizado

Playa del Carmen es un destino que tiene un promedio de estancia de dos a cinco días, principalmente por el segmento nacional, que arriba en vacaciones de Semana Santa, de verano, en invierno y los fines de semana. Las personas con estancias más prolongadas provienen de centros geográficos distantes (figura 14).
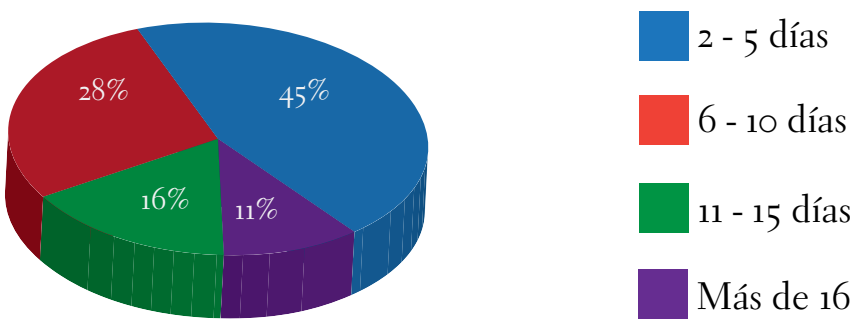

Figura 14. Estancia promedio 
Como se aprecia en la figura 15, Playa del Carmen sigue siendo un destino de primera vez con casi $60 \%$, sin embargo existe un segmento importante que es reincidente, y por las condiciones del destino muchas de las personas regresan e incluso se vuelven residentes.

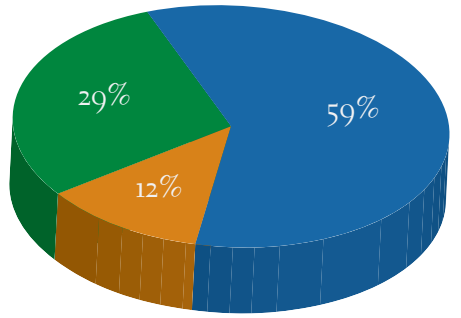

Primera vez

Dos veces al año

Más de dos veces al año

Figura 15. Frecuencia de visita

Para determinar el motivo principal del viaje a Playa del Carmen se establecieron diferentes categorías, en el instrumento de recolección de datos se permite cotejar las respuestas cuando se pregunta sobre las actividades específicas realizadas a lo largo de la estancia. Las respuestas concuerdan porcentualmente con las actividades desarrolladas. Ahora bien, como se aprecia en la figura 16, $68.4 \%$ de la muestra visita este destino de playa con el principal objetivo de tener un momento de ocio y relajación.

En segundo lugar se realizó turismo de aventura, con un porcentaje de $15.7 \%$; es de destacar que en tercer lugar se encuentre el segmento empresarial, por la dinámica y crecimiento acelerado de Playa del Carmen hay muchas personas que vienen por cuestiones laborales, y en sus tiempos libre hacen uso de los recursos turísticos. Con $2 \%$ podemos identificar al turismo de naturaleza, aunque tácitamente las actividades de sol y playa deberían entrar en este segmento por su importancia, pero para permitir un desglose de actividades se separó en una categoría diferente.

Cotejando las respuestas de la pregunta anterior sobre el motivo principal del viaje con las actividades realizadas durante la estancia es que se ratifican las respuestas; con un porcentaje de $76.9 \%$ encontramos las actividades de sol y playa, que se relacionan directamente con el ocio, el tiempo libre y la relajación; en segundo lugar, con $26.3 \%$, se encuentran las actividades culturales, 


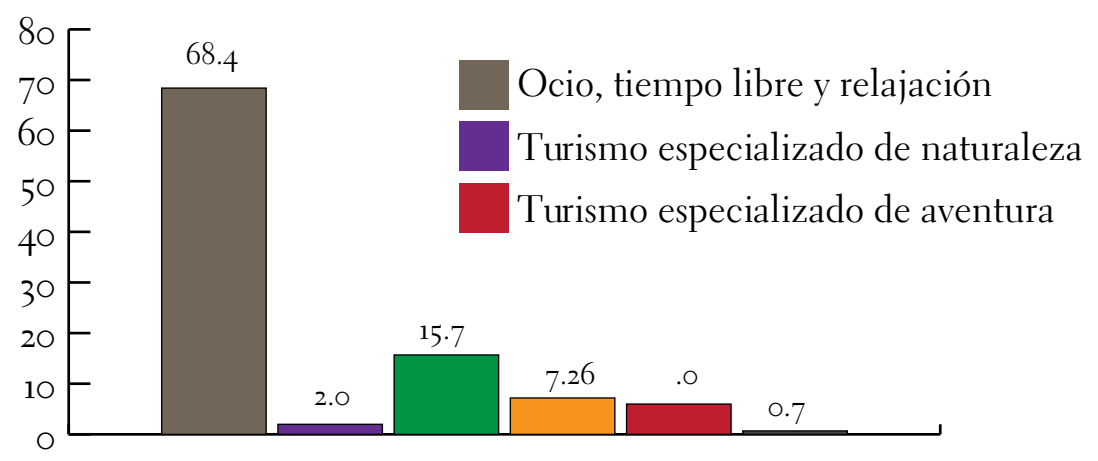

Figura 16. Motivo principal del viaje

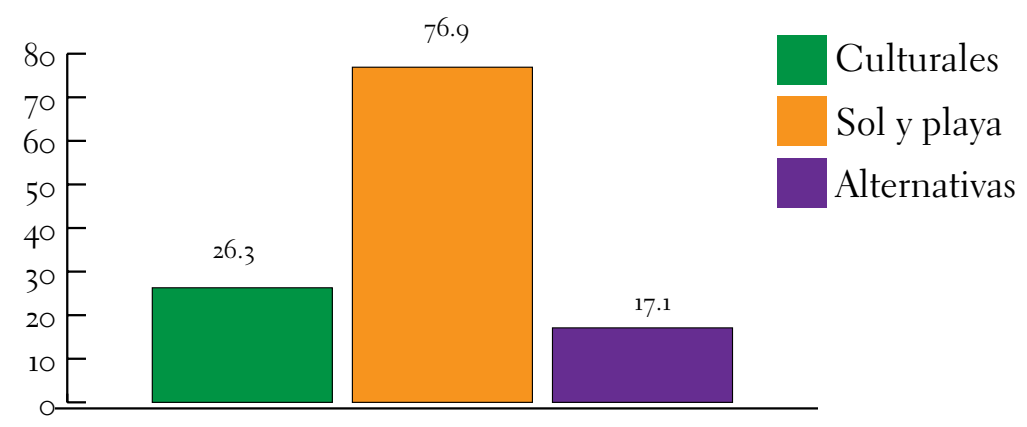

Figura 17. Actividades realizadas durante la estancia

que identifican a los turistas plenamente con el conocimiento y éste a su vez con conocer sitios arqueológicos, principalmente. En 17.1\% se encuentran las actividades alternativas, asociadas a naturaleza y aventura. Como se puede apreciar el porcentaje en esta pregunta es mayor a $100 \%$ ya que algunos turistas realizan más de una actividad durante su estancia. Por lo cual el acumulativo es de $120.3 \%$. 
El cien por ciento de la pregunta relativa a actividades culturales corresponde a 40 casos muestrales que contestaron afirmativamente; $85 \%$ de los visitantes que realizaron este tipo de actividades las relacionaron con el conocimiento y el aprendizaje, que como ya se ha mencionado se asocia con visitas a zonas arqueológicas mayas y visitas a comunidades indígenas.

De las actividades que se desarrollan de sol y playa (figura 18) la principal es la de descanso y relajación con $80.3 \%$ de respuestas; es decir estar la mayor parte del tiempo disfrutando de la arena, el sol y el mar. En segundo lugar figura el entretenimiento nocturno, con un porcentaje de $21.3 \%$, esto derivado de la gran oferta de bares y discotecas principalmente sobre la Quinta Avenida y la Calle 12. El porcentaje en esta pregunta corresponden a 132 casos muestrales que contestaron sí a las actividades de sol y playa; el porcentaje en esta pregunta es mayor a $100 \%$ ya que algunos turistas realizan más de una actividad. El porcentaje acumulativo en esta pregunta asciende a $112.7 \%$.

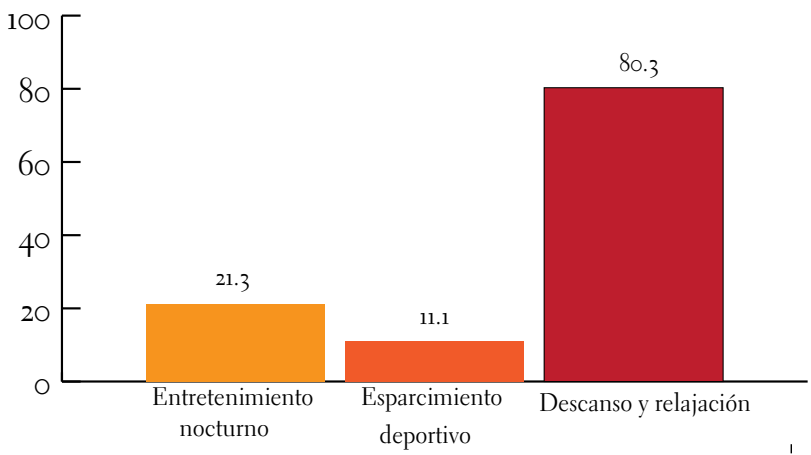

Figura 18. Actividades de sol y playa

Dieciocho casos muestrales contestaron sí a las actividades alternativas; el porcentaje en esta pregunta es mayor a $100 \%$ ya que algunos turistas realizan más de una actividad durante su estancia, por lo que el acumulativo corresponde a $115.3 \%$. Como se observa en la figura 19, realizan actividades de turismo de aventura $76.9 \%$ de los entrevistados y $19.2 \%$ actividades de naturaleza y de eventos programados. En la Riviera Maya donde se ubica Playa del Carmen se presentan principalmente el Festival de Jazz de la Riviera Maya, el Festival de Música bpm, el Festival de Música Arena, y la Travesía Maya. 


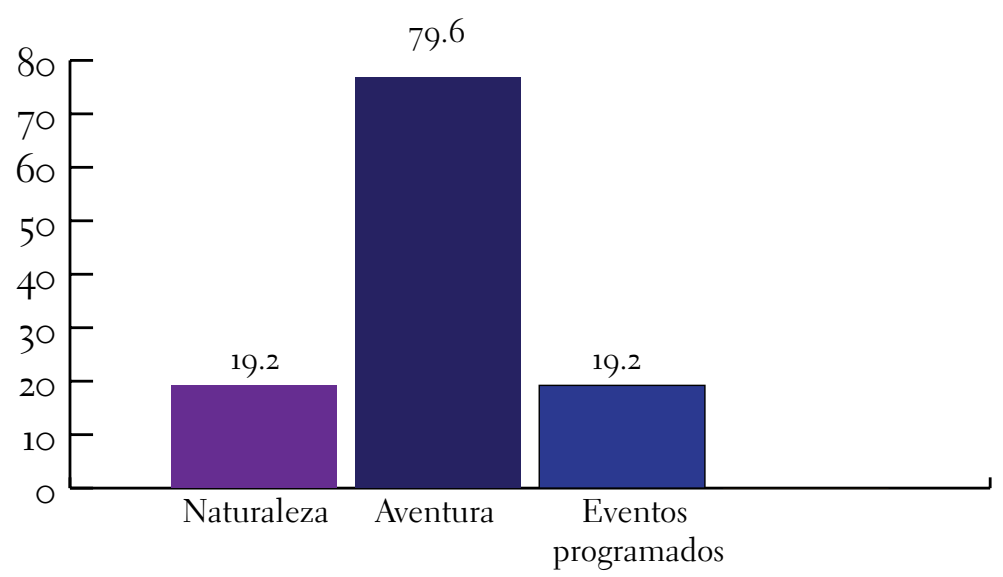

Figura 19. Actividades de turismo alternativo

Las principales actividades especializadas que se desarrollan en Playa del Carmen relacionadas con el turismo de naturaleza son las visitas guiadas, la observación de fauna y de flora, con un porcentaje de $2.6 \%$. El porcentaje en esta pregunta es menor a $100 \%$ ya que sólo se consideran los turistas que realizaron una o varias actividades de naturaleza durante su estancia. El porcentaje acumulativo de la muestra alcanza apenas $7.8 \%$ (figura 20).

Las principales actividades identificadas en el turismo de aventura terrestre son la escalada, el senderismo y el trekking, con porcentajes que alcanzan un máximo de $5.2 \%$. El porcentaje en esta pregunta es menor a 100\%, ya que sólo se consideran los turistas que realizaron una o varias actividades durante su estancia. El porcentaje acumulativo de la muestra alcanza sólo 18.9\% (figura 21).

Las principales actividades identificadas en el turismo de aventura en modalidad acuática son el buceo con $10.5 \%$ lo cual se debe al segundo arrecife coralino más grande del mundo y a la claridad del agua del caribe mexicano. En segundo lugar encontramos la práctica del kayak con un porcentaje de 5.9\%. El porcentaje en esta pregunta es menor a $100 \%$ ya que solo se consideran los turistas realizaron una o varias actividades de aventura en modalidad acuática durante su estancia. El porcentaje acumulativo del total de la muestra alcanza solo $21.1 \%$ (figura 22 ). 


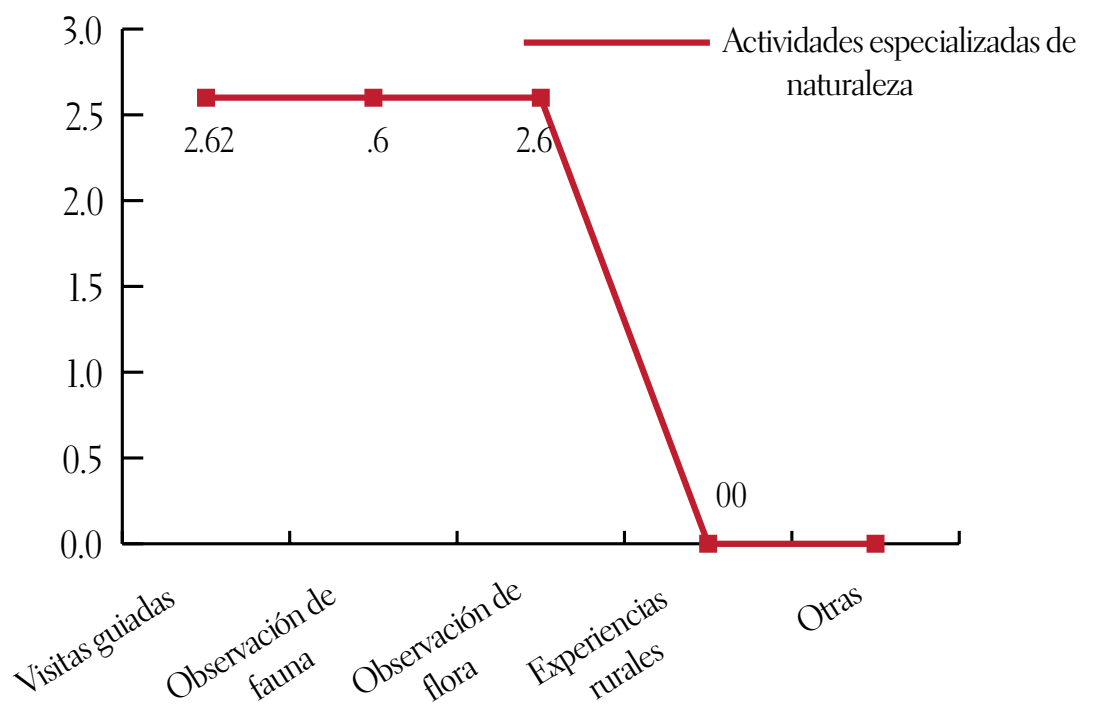

Figura 20. Actividades especializadas de naturaleza

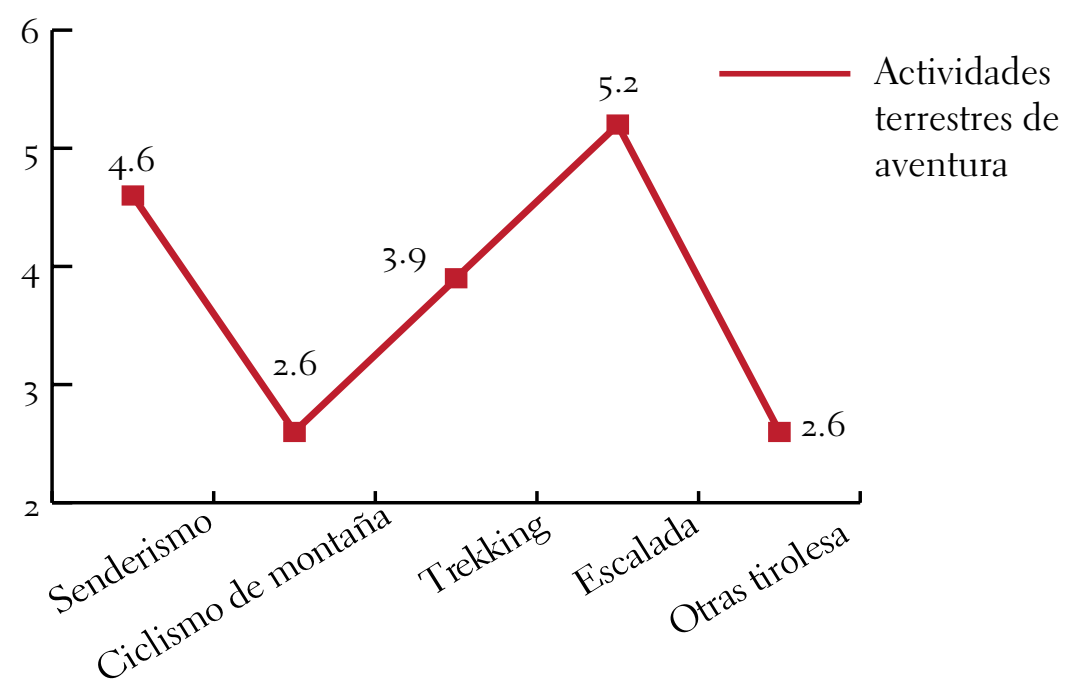

Figura 21. Actividades terrestres de aventura 


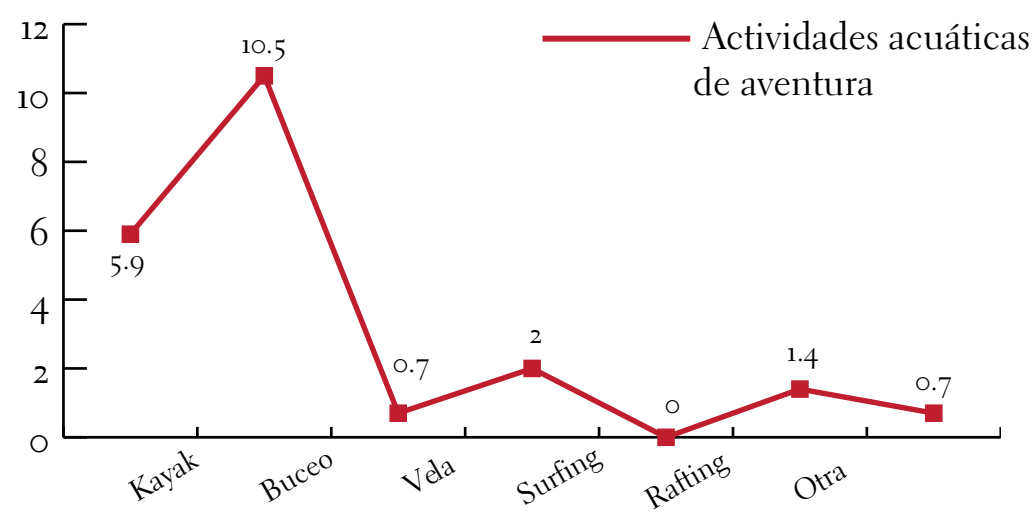

Figura 22. Actividades acuáticas de aventura

Las principales actividades identificadas en el turismo de aventura en modalidad aérea son el paracaidismo, con un $6.5 \%$, seguido de la práctica del parapente con un porcentaje de $1.4 \%$. El porcentaje en esta pregunta es menor a $100 \%$ ya que sólo se consideran los turistas que realizaron una o varias actividades de aventura en modalidad aérea durante su estancia. El porcentaje acumulativo de la muestra alcanza sólo 8.6\% (figura 23).

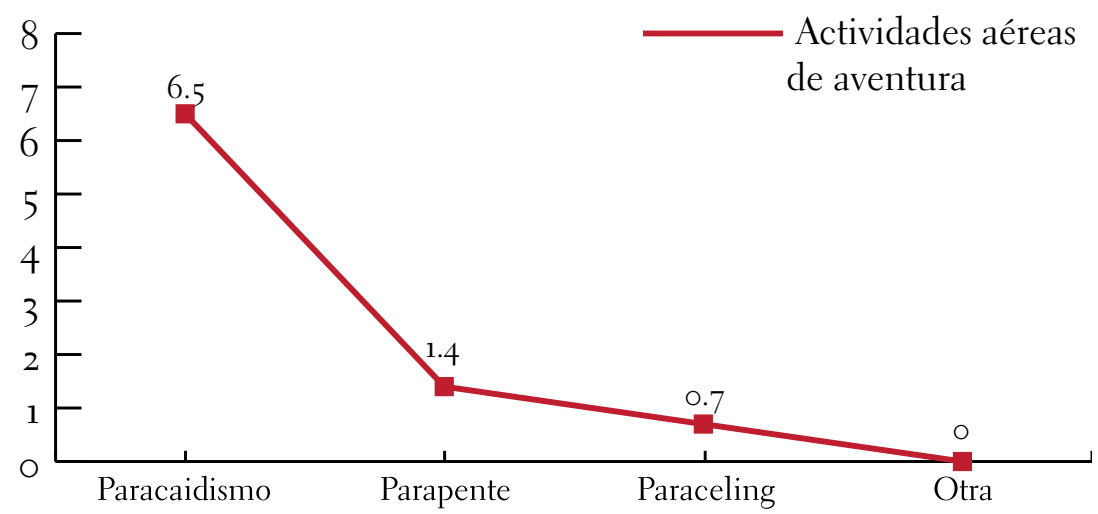

Figura 23. Actividades aéreas de aventura 
Inferencia de datos entre la muestra y los segmentos de turismo de aventura y de naturaleza

Para llevar a cabo las inferencias, sólo se considerará los segmentos de turismo de naturaleza y aventura, ya que son el objeto de estudio.

El sexo femenino del segmento de turismo y de aventura alcanza sólo 2.1\% del tamaño de la muestra; en contraparte, el sexo masculino registra 15.8\% lo que representa aproximadamente una quinta parte de la muestra (figura 24).

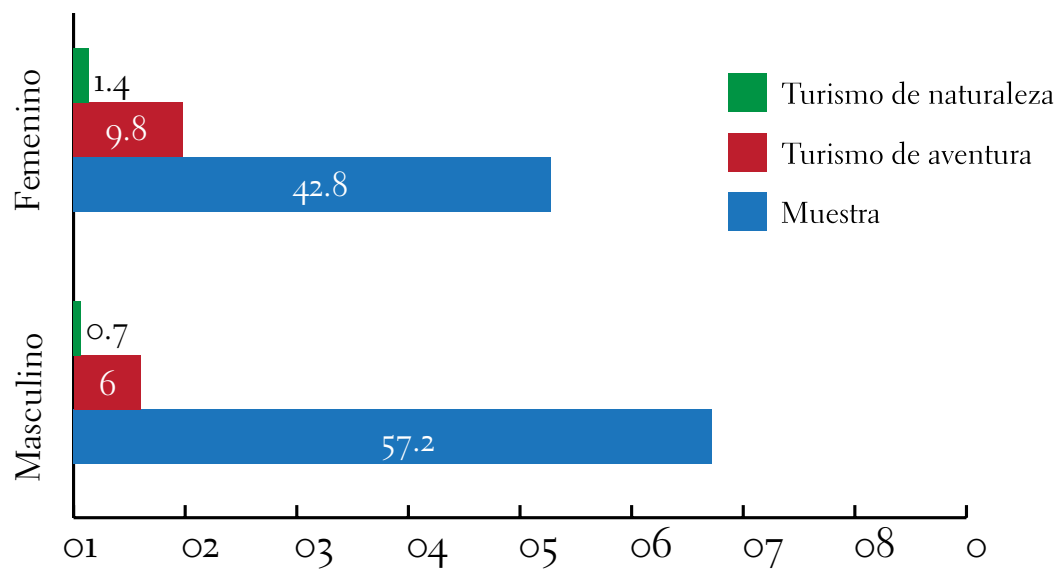

Figura 24. Comparativo del sexo de la demanda turística en Playa del Carmen por segmento de turismo

En lo que respecta a los rangos de edad del turismo de aventura y naturaleza se encuentra que el principal segmento oscila porcentualmente en un 15.1 de un $53.9 \%$ en el rango de 18 a 35 años de edad; siendo éste el más representativo, lo que nos da como resultado que el segmento de turistas que buscan actividades de aventura y naturaleza es de adultos jóvenes (figura 25).

Como se aprecia en el comparativo de la profesión u ocupación del segmento de turismo de aventura y naturaleza los estudiantes son lo que ocupan el mayor porcentaje, con $8.5 \%$, seguido por los profesionistas con $7.3 \%$ (figura 26). 


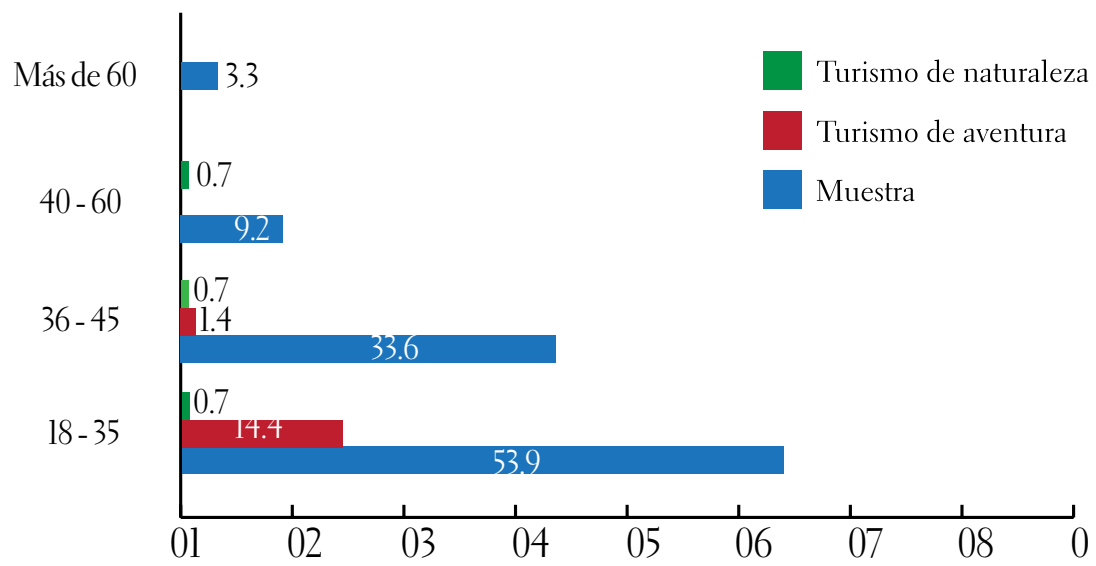

Figura 25. Comparativo de la edad de la demanda turística en Playa del Carmen por segmento de turismo

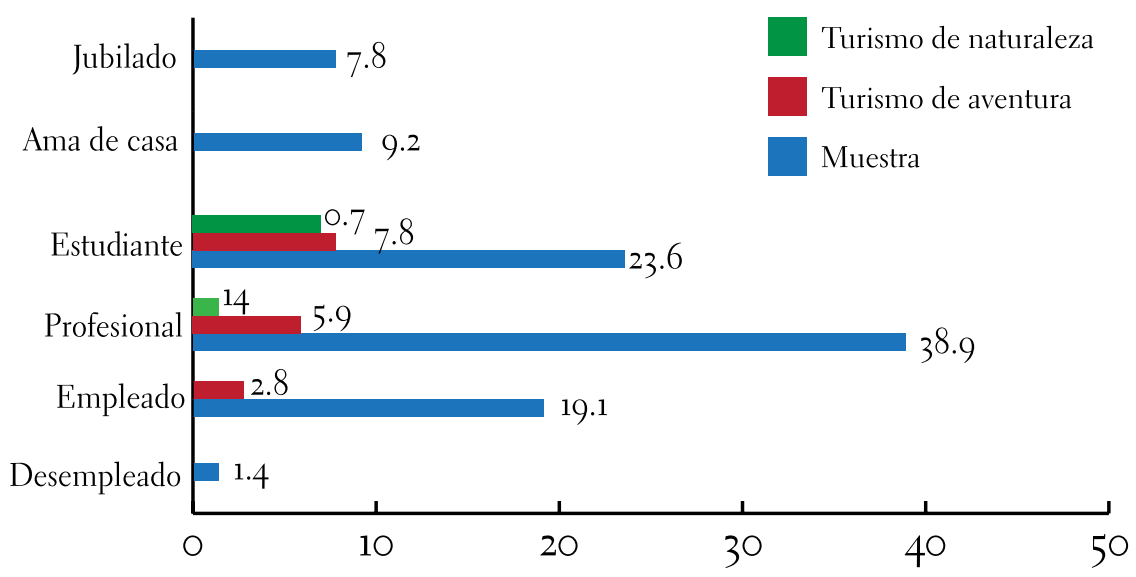

Figura 26. Comparativo de la profesión u ocupación de la demanda turística en Playa del Carmen por segmento de turismo 
Como se aprecia en la figura 27, el grado de preparación con el que cuentan los visitantes del segmento turismo de aventura y naturaleza representa $14.6 \%$, seguido por los que tienen el nivel de preparatoria con $3.1 \%$, dejando fuera los demás grados académicos.

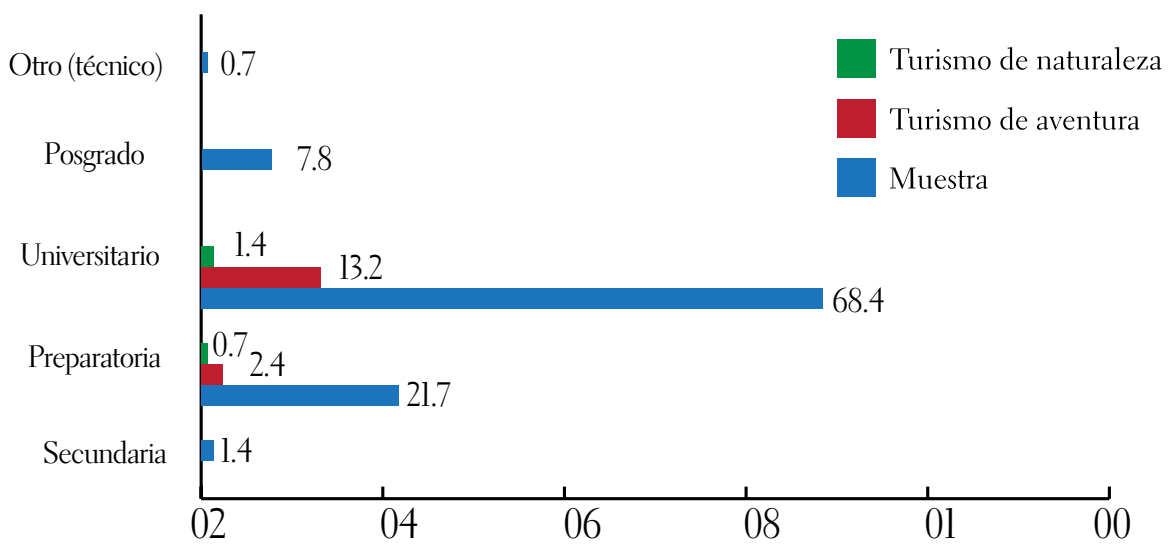

Figura 27. Comparativo del nivel de estudios de la demanda turística en Playa del Carmen por segmento de turismo

La procedencia más frecuente de los visitantes que practican turismo de aventura y de naturaleza en Playa del Carmen es del interior del país, con 11.2\% de la muestra, seguido de Estados Unidos y Canadá, con un porcentaje de 3.9\% (figura 28).

Los turistas que desarrollan actividades de turismo de naturaleza y de aventura viajan generalmente con amigos, como se aprecia en la figura 29, con un porcentaje de $11.8 \%$ seguido por un segmento de personas que viajan con su pareja, ocupando el 3.5 de la muestra.

La estancia promedio del segmento de turistas de naturaleza y aventura va 6 a 10 días y de 11 a 15 días con un promedio general 6\%. Lo que implica que las personas que hacen actividades relacionadas con sus segmentos son los que tienen más tiempo en el destino (figura 30). 


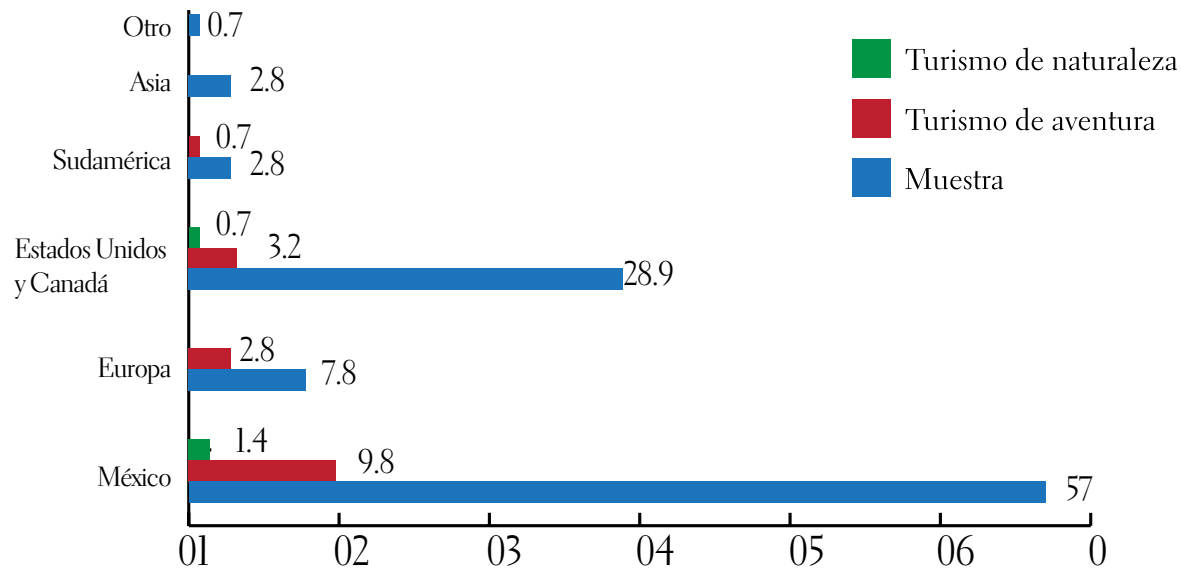

Figura 28. Comparativo del lugar de residencia de la demanda turística en Playa del Carmen por segmento de turismo

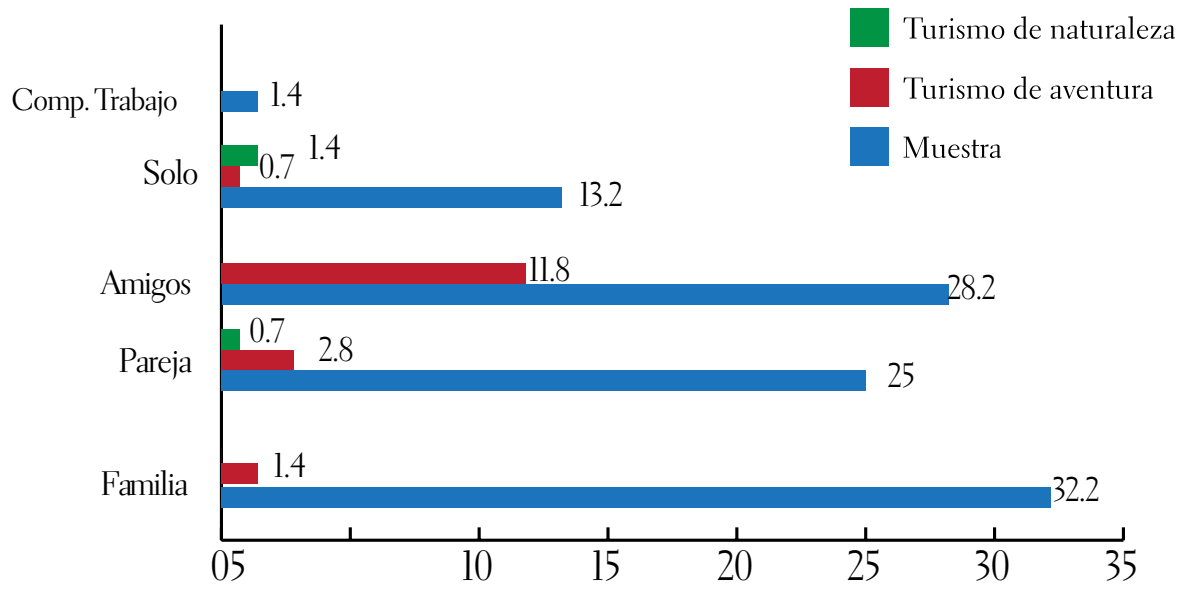

Figura 29. del con quien viaja de la demanda urística en Playa del Carmen por segmento de turismo 


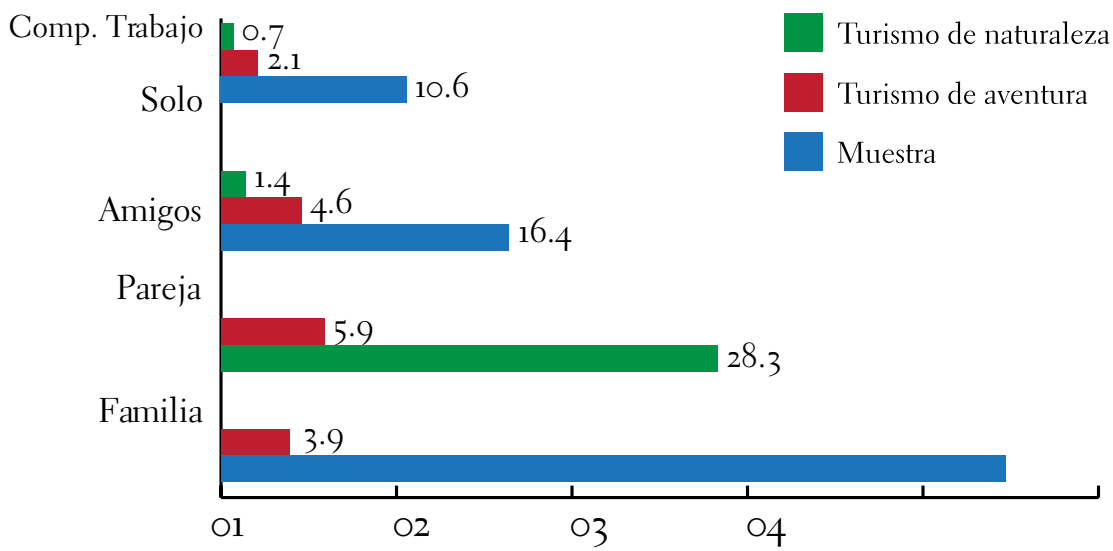

Figura 30. Comparativo de promedio de estancia de la demanda tứŕs7 tica en Playa del Carmen por segmento de turismo

Inferencia entre el motivo principal el viaje y las actividades realizadas

Motivo principal del viaje

Naturaleza

Aventura

$2 \%$

$15.7 \%$

$17.7 \%$

Actividades

genéricas realizadas

durante la estancia

Naturaleza y

aventura

$17.1 \%$

Como se aprecia en el cuadro anterior la relación entre el motivo principal del viaje y las actividades realizadas durante la estancia son congruentes entre sí, lo que nos permite determinar que casi una quinta parte $(1 / 5)$ del turismo que visita Playa del Carmen pertenece al segmento de turismo de aventura y naturaleza, aunque como se aprecia adelante el porcentaje de las actividades 
realizadas por el segmento de naturaleza corresponde a $7.8 \%$ y el de aventura $48.7 \%$; sumando ambos segmentos asciende a $56.5 \%$, por lo que es importante recapitular que los turistas han realizado más de una actividad y que los porcentajes están por arriba de $100 \%$. Es decir, no se puede definir que haya un turista puro.

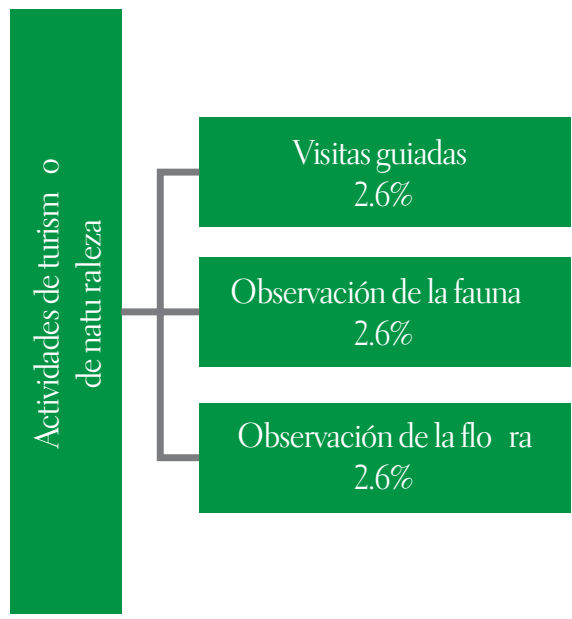

Figura 31. Principales actividades de naturaleza en Playa del Carmen

\section{Actividades predominantes por segmento en Playa del Carmen}

Como se observa en la figura 31 las actividades de turismo de naturaleza se encuentran homogéneamente distribuidas, encontrándose las tres que definen al segmento y en la misma proporción.

Las principales actividades de aventura que se desarrollan en Playa del Carmen son el buceo, el paracaidismo, el kayak, la escalada, el senderismo y el trekking y en menor escala la tirolesa, el ciclismo de montaña, el surfing, la pesca, el parapente y, finalmente, en menos proporción, el snorkeling, la vela y el paraceling. 
Escalada $5.2 \%$

Senderismo $4.6 \%$

Trekking 3.95\%

Tirolesa $2.6 \%$

Ciclismo de mont aña $2.6 \%$

Aventura terrestre

Aventura acuática
Buceo 10.5\%

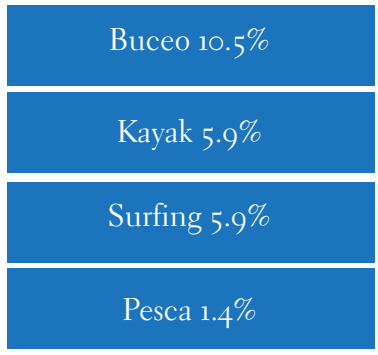

Snorkeling $0.7 \%$

Vela $0.7 \%$
Paracaidismo $6.5 \%$

Parapente $1.4 \%$

Paraceling $0.7 \%$

Figura 32. Distribución porcentual de las actividades de naturaleza en Playa del Carmen

Características principales de los turistas que hacen uso de los recursos de turismo de naturaleza y aventura en Playa del Carmen

El sexo predominante que realiza actividades de turismo de aventura y naturaleza en Playa de Carmen es femenino. La edad promedio es de 18 a 35 años, generalmente son estudiantes; el nivel de estudios es superior. Por lo general viajan con amigos o con sus parejas y el promedio de estancia es de 6 a 10 días.

Los principales centros emisores nacionales de segmento de turistas de naturaleza y aventura y naturaleza hacia Playa del Carmen son: el Distrito Federal, Guadalajara, Monterrey, Veracruz, Mérida y Toluca. En cuanto que al turismo extranjero, provienen principalmente de Estados Unidos y Canadá.

Las principales actividades que realizan son buceo, paracaidismo y kayak. 


\section{Conclusiones}

Aproximadamente $17 \%$ del turismo que llega a Playa del Carmen hace uso de recursos del segmento de naturaleza y aventura. Esto no quiere decir que los turistas vengan con esa motivación, realmente el mercado que maneja este destino es de sol y playa y cuestiones culturales, principalmente de los mayas, su cultura, tradiciones y zonas arqueológicas.

Las actividades características de estos segmentos no son el motivo del viaje, sino que son ofrecidas a los turistas en sus centros de hospedaje, por el propio hotel o por los representantes de las agencias de viaje y tour operadores con los que viene el visitante.

Las actividades no se realizan de manera independiente casi siempre son parte de los tour que se adquieren. La única excepción es el buceo, ya que genera un desplazamiento importante no sólo a Playa del Carmen, sino a todo el Caribe mexicano.

Lo que implica que los turistas de este segmento son consecuenciales, objeto de la promoción de dichas actividades una vez ya que están en el destino, sin embargo se puede potenciar atendiendo a los gustos de los turistas y desarrollando productos turísticos.

Considerando los resultados, el objetivo general se cumple al identificar a través de las actividades que realizan los turistas durante su estancia cuál es la dimensión demandada de recursos de turismo de naturaleza y aventura, considerando que no se encontró un turista puro; es decir, que viniera exclusivamente con esa motivación de viaje. En lo que respecta a los objetivos específicos se estableció cuáles son las actividades que más se llevan a cabo en Playa del Carmen y se identificó el perfil del turista.

Dentro de las limitaciones del presente trabajo de investigación, el principal es el tiempo, ya que la muestra fue tomada en un lapso de temporada baja por lo cual la muestra no es representativa, aunque como un estudio exploratorio nos da un parámetro de análisis.

La otra limitación importante es la conceptualización del turismo, como se menciona en el marco teórico, el turismo de naturaleza, de aventura, ecológico, extremo, deportivo, comúnmente son confundidos. Aun así en el desarrollo de la investigación se trató de ajustar teóricamente lo más posible a la clasificación y recomendaciones al respecto de la Organización Mundial de Turismo. 
Dentro de las posibilidades de la investigación ésta nos facultaría para hacer un análisis de todos los segmentos de turismo y determinar cuáles son las actividades más desarrolladas; generar estrategias de desarrollo de infraestructura y estructura turística así como promocionales para todo el destino y no sólo para un determinado segmento.

Para futuras investigaciones derivadas de ésta se puede determinar también la vocación turística de Playa del Carmen.

\section{Recomendaciones}

Para llevar a cabo una investigación de la temática planteada de manera más completa y representativa se recomienda:

Recolectar los datos abarcado los periodos vacacionales más importantes del año: Semana Santa, vacaciones de verano y de invierno, así como los fines de semana largos, para hacer la investigación representativa. Con la muestra obtenida de manera anual y siendo ésta característica, elaborar indicadores que permitan analizar de manera más acertada los tipos de recursos y actividades realizadas por los turistas en Playa del Carmen.

Obtener datos estadísticos, como la desviación estándar, la varianza, el error muestral, la media, la moda y la mediana, para realizar proyecciones e identificar las oportunidades de desarrollo de proyectos acorde a la demanda del destino.

Complementar la recolección de datos mediante entrevistas a los prestadores de servicios turísticos, tour operadores y agencias de viajes, para determinar las principales actividades realizadas por la demanda turística y establecer la motivación principal de los turistas que visitan Playa del Carmen.

Determinar la afluencia turística no sólo por país, sino por región o ciudad, nacional y del extranjero, para facultar la identificación de hacia dónde enfocar los esfuerzos de publicidad y promoción.

Establecer los motivos por los que se escoge alguna actividad mediante la identificación de gustos y preferencias para fomentar el gasto promedio de los turistas en el destino de Playa del Carmen. 


\section{Literatura consultada}

Acerenza, M. A. (2005). Administración del turismo. Conceptualización y organización. México: Trillas.

Boullón, R. C. (2004). Planificación del espacio turístico. México : Trillas.

Cárdenas Tabares , F. (2009). Proyectos turísticos, localización e inversión. México: Trillas.

De la Torre Padilla , O. (2012). Turismo actividad mundial: antecedentes históricos, evolución mundial y desarrollo en México. México: Trillas.

Gobierno del Estado de Quintana Roo (septiembre 2012). Portal del Gobierno de Quintana Roo. Recuperado de http://www.qroo.gob.mx/qroo/ WebPage.php?Pagina $=$ Gabinete.php\&IdRubro $=7$ (2001). Ley de equilibrio ecológico y la protección del medio ambiente del estado de Quintana Roo. Recuperado de http://inira.qroo.gob.mx/ portal/archivo/LEEPA.pdf

Gobierno del Municipio de Solidaridad (agosto 2012). H. Ayuntamiento de Solidaridad. Recuperado de http://www.solidaridad.gob.mx/2011/index. php?option $=$ com_content $\&$ view $=$ article\&id $=92 \&$ Itemid $=192$

Gurría Di-Bella, M. (2007). Introducción al turismo. México: Trillas. Molina , S. (1997). Conceptualización del turismo. México: Limusa.

Quesada Castro, R. (2007). Elementos del turismo. San José de Costa Rica: EunED. Sampieri, R., Fernández Collado, C. y Baptista Lucio, P. (2010). Metodología de la investigación. México: McGraw Hill.

Sancho , A. y Buhalis, D. (1998). Introducción al turismo. Madrid: omt.

SIImt (2011). Glosario de términos utilizados para la promoción de la promoción de turismo. Recuperado de http://www.siimt.com/work/sites/siimt/ resources/LocalContent/1963/3/PDF_Glosario2.pdf

Turismo, O. M. (2012, 15 de octubre). Entender el turismo: glosario básico. Obtenido de http://media.unwto.org/es/content/entender-el-turismoglosario-basico\#Destino

Vasconi , M. y Togni, A. (1996). Aproximación a la eficacia del sistema turístico. Centro de investigación y capacitación empresarial, 1(194).

Vignati Scarpati, F. A. (2009). Gestión de destinos turísticos: Cómo atraer personas a polos, ciudades y países. México: Trillas.

Zamorano Casal, F. M. (2009). Turismo alternativo. Servicios turísticos diferenciados. México: Trillas. 